\title{
Questes
}

\section{Conclusions : Finir le Moyen Âge}

\section{Pauline Guena et Annabelle Marin}

\section{(2) OpenEdition}

\section{Journals}

\section{Édition électronique}

URL : http://journals.openedition.org/questes/4311

DOI : 10.4000/questes.4311

ISSN : 2109-9472

\section{Éditeur}

Les Amis de Questes

\section{Édition imprimée}

Date de publication : 10 juin 2016

Pagination : 127-128

ISSN : 2102-7188

\section{Référence électronique}

Pauline Guena et Annabelle Marin, «Conclusions : Finir le Moyen Âge », Questes [En ligne], 33 | 2016, mis en ligne le 15 juin 2016, consulté le 15 septembre 2020. URL : http://journals.openedition.org/ questes/4311 


\section{Conclusions : Finir le Moyen Âge}

\section{Pauline GuÉNA et Annabelle MARIN}

Université Paris-Sorbonne

Les six contributions présentées ici par des masterants et doctorants en archivistique, en littérature médiévale, en histoire médiévale et en histoire moderne se sont concentrées sur l'Occident, s'interrogeant autant sur le «passage » d'une époque à l'autre, que sur ses modalités. Matthieu Pène a évoqué ainsi les contraintes historiques qui ont poussé à la périodisation archivistique dont nous héritons aujourd'hui. Roseline FoltzAmable et Oury Goldman ont envisagé de part et d'autre de la scansion entre époque médiévale et époque moderne la manière et les temporalités selon lesquelles meurent ou naissent des pratiques d'écriture ou de connaissance. Cette question des temporalités s'est alors décliné à travers quatre terrains d'étude, dont les premiers relèvent de l'hommage à Jacques le Goff: la ville, et plus particulièrement la ville de Nantes étudiée par Aurore Léon, la façon dont les femmes s'insèrent en ville par le travail sur laquelle s'est penché Julie Pilorget et enfin la difficile transmission d'une première traduction de Virgile, présentée par Lucien Dugaz. La diversité des réponses apportées par ces contributions relève peut-être de leur champ d'étude ou de leur domaine universitaire. La rupture époque médiévale-époque moderne se fait par exemple plus marquée dans le travail d'Oury Goldman ou de Roseline Foltz-Aimable, que dans celui d'Aurore Léon. Pourtant il semble que la focale choisie joue également un grand rôle : que l'on étudie un livre, un mouvement 
littéraire ou encore une culture de mise en forme du savoir, les temporalités détectées ne sauraient être les mêmes, et le Moyen Âge ne saurait avoir la même fonction. 